\title{
Optical absorption and fluorescence spectroscopy studies of Artepillin C, the major component of green propolis
}

\author{
Isamara Julia Camuri a , Adriano Batista Costa ${ }^{\mathrm{a}}$, Amando Siuiti Ito ${ }^{\mathrm{a}}$, Wallance Moreira Pazin ${ }^{\mathrm{b}, *}$ \\ a Department of Physics, Faculty of Philosophy, Sciences and Letters of Ribeirão Preto, University of São Paulo (USP), Ribeirão Preto, SP, Brazil \\ ${ }^{\mathrm{b}}$ Department of Physics, School of Sciences and Technology, São Paulo State University (UNESP), Presidente Prudente, SP, Brazil
}

\section{A R T I C L E I N F O}

\section{Article history:}

Received 9 November 2017

Received in revised form 7 February 2018

Accepted 22 February 2018

Available online 23 February 2018

\section{Keywords:}

Green propolis

Artepillin C

Optical spectroscopy

pH effects

Aggregation properties

\begin{abstract}
A B S T R A C T
The bioactivity of propolis against several pathogens is well established, leading to the extensive consumption of that bee product to prevent diseases. Brazilian green propolis, collected by the species Apis mellifera, is one of the most consumed in the world. The chemical composition of green propolis is complex and it has been shown that it displays antioxidant, antimicrobial, anti-inflammatory and antitumor activities, especially due to the high content of Artepillin C. The molecule is a derivative of cinnamic acid with two prenylated groups, responsible for the improvement of the affinity of the compound for lipophilic environment. A carboxylic group $(\mathrm{COOH})$ is also present in the molecule, making it a pH-sensitive compound and the pH-dependent structure of Artepillin C, may modulate its biological activity related to interactions with the cellular membrane of organisms and tissues. Molecular properties of Artepillin C on aqueous solution were examined by optical absorption, steady state and time-resolved fluorescence spectroscopies. Acid-base titration based on the spectral position of the near UV absorption band, resulted in the pKa value of 4.65 for the carboxylic group in Artepillin C. In acidic pH, below the pKa value, an absorption band raised around $350 \mathrm{~nm}$ at Artepillin C concentration above $50 \mu \mathrm{M}$, due to aggregation of the molecule. In neutral pH, with excitation at $310 \mathrm{~nm}$, Artepillin $\mathrm{C}$ presents dual emission at 400 and $450 \mathrm{~nm}$. In pH close to the pKa, the optical spectra show contribution from both protonated and deprotonated species. A three-exponential function was necessary to fit the intensity decays at the different pHs, dominated by a very short lifetime component, around $0.060 \mathrm{~ns}$. The fast decay resulted in emission before fluorescence depolarization, and in values of fluorescence anisotropy higher than could be expected for monomeric forms of the compound. The results give fundamental knowledge about the protonation-deprotonation state of the molecule, that may be relevant in processes mediated by biological membranes.
\end{abstract}

(C) 2018 Elsevier B.V. All rights reserved.

\section{Introduction}

The protection of beehives against intruders is guaranteed by the plant resins collected by the bees to produce the propolis, that, in Greek, means "pro = in defense" and "polis = city" [1]. The final product is constituted mainly by the mixture of the resinous compounds and beeswax, enabling bees to seal their nests for the asepsis [2]. Ancient civilization took advantage of the biological properties of propolis to be used in folk medicine, for instance as anti-pyretic, antiseptic and cicatrizing agent [3]. Since then, propolis has been extensively consumed in food and beverages until nowadays as a popular remedy to prevent diseases and act against several pathogens, mainly due to its established antimicrobial properties [4].

The chemical composition of propolis is complex and dependent on the region that bees can access to collect the resinous compounds, but it

* Corresponding author at: Departamento de Física, FCT - UNESP, Presidente Prudente, SP, Rua Roberto Simonsen, 305, 19060-900 Presidente Prudente, São Paulo, Brazil.

E-mail address: wallancepazin@gmail.com (W.M. Pazin). is known that bees search for secondary metabolites synthetized by the plant enzymes to ensure its biological protection [5]. In European countries and China, for instance, the major constituents of propolis are several classes of flavonoids and phenolic acid esters, while in Brazil, besides the presence of flavonoids, most of propolis is constituted mainly by terpenoids and prenylated derivatives of $p$-coumaric acid [6,7]. Among all Brazilian propolis, the green propolis, processed by bee species Apis mellifera, is one of the most consumed propolis in the world, mainly in Japan [8]. It has been shown that this propolis displays antioxidant, antimicrobial, anti-inflammatory and antitumor activities, especially due to the high amount of Artepillin C, a cinnamic acid derivative that presents two prenylated groups (Fig. 1), responsible to improve the affinity of the compound for lipophilic environment, for instance biological membranes, in the biological action in target cells [3,9-12].

Artepillin $\mathrm{C}$ also present the carboxylic acid group $(\mathrm{COOH})$, bringing it to a particular class of $\mathrm{pH}$-sensitive compounds. It has been established that, due to the differences in the molecular structure of such compounds dependent on the $\mathrm{pH}$ of the medium, they might be 
selective in their biological actions [13]. A correlation between biological properties of Artepillin C and its particular structure may exist: it is thought that the compound, in healthy physiological conditions, improves the antioxidant potential of the biological system via one-step hydrogen atom transfer mostly by interacting with cell membranes, probably due to the presence of prenylated groups, avoiding the formation of lipid peroxidation caused by free radicals that damage membrane structure with low toxicity [14,15]. Antioxidant potential also were tested for Artepillin C derivatives, which displayed remarkable enhancement of scavenging radical activities [16]. Meanwhile, an interestingly particular feature of tumor cells is the acidic extracellular matrix resulting from the lactate production through the anaerobic glycolytic pathway for energy generation of the cells $[13,17]$. The low $\mathrm{pH}$ of extracellular matrix may change the protonation state of $\mathrm{pH}$-dependent bioactive compounds, such as Artepillin C, probably modulating its action to damage the cellular membrane of tumor cells, as known for other compounds [13].

The biological characteristics above described motivated us to investigate the molecular properties of Artepillin C on aqueous solution, since most of biological molecules are embedded in fluids, especially water. This study was performed by optical absorption, steady state and time-resolved fluorescence spectroscopies, which are powerful and sensitive techniques to evaluate the protonation state, the aggregation state and the hydrophobic-hydrophilic characteristics of many natural compounds [18].

\section{Material and Methods}

\subsection{Material}

Artepillin C, isolated and purified (98.43\%) from green propolis, was purchased from Apis Flora (Ribeirão Preto, SP, Brazil). Phosphate, citric acid and methanol of analytical grade were obtained from Sigma Chemical Co. (St. Louis, MO, USA). Aqueous solutions were prepared with ultrapure Milli-Q® water.

\subsection{Optical Absorption and Fluorescence Measurements}

Firstly, in acid-base titration experiments, citrate (0.1 M, pH 2.6) and phosphate ( $0.2 \mathrm{M}, \mathrm{pH} 9.2)$ buffers were prepared and, from a citratephosphate mixture, 25 samples were obtained with $\mathrm{pH}$ value in the

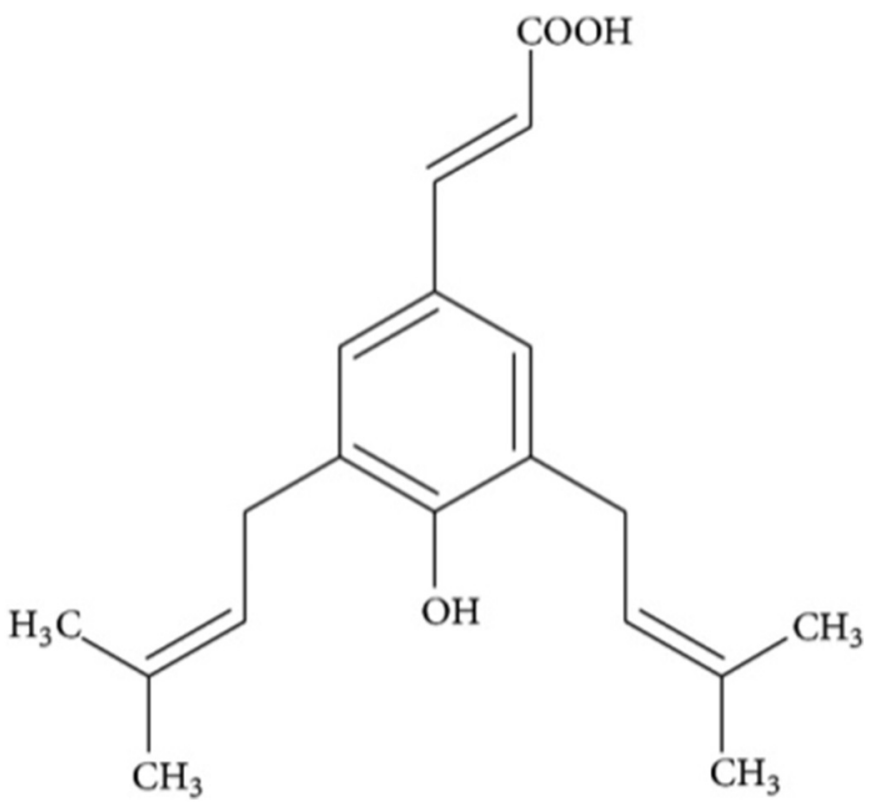

Fig. 1. Molecular structure of Artepillin C.

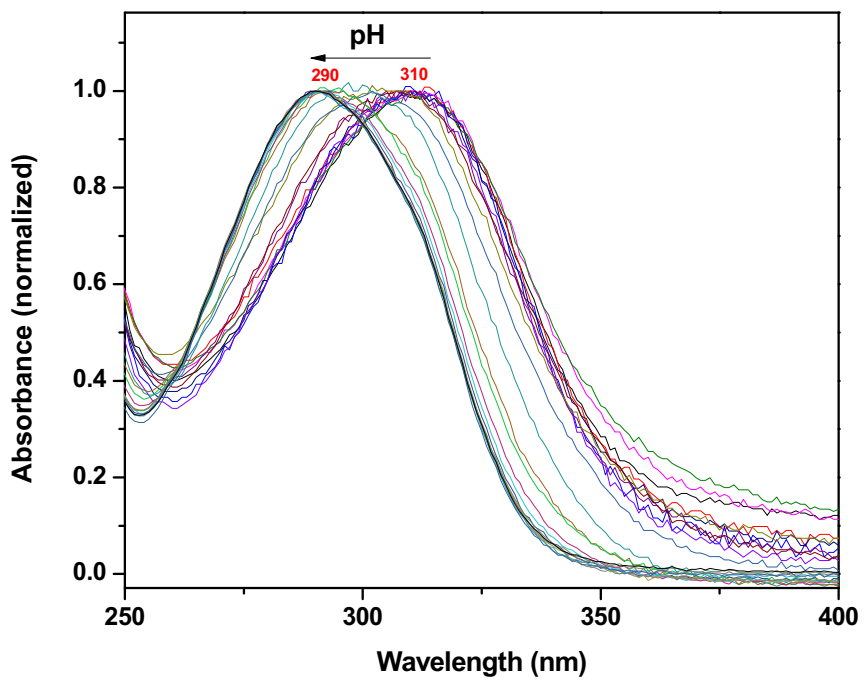

Fig. 2. Optical absorption spectra of Artepillin C $20 \mu \mathrm{M}$ measured in the pH range 2.6 to 9.2. Spectra normalized in the maximum intensity of the absorption band. Temperature $25^{\circ} \mathrm{C}$

interval 2.6 to 9.2. An aliquot from a stock solution of Artepillin C in methanol (30 mM) was injected into each citrate-phosphate buffer solution, so that the concentration of the compound was $20 \mu \mathrm{M}$ in the samples at different $\mathrm{pH}$ values. From optical absorption spectra, a titration curve was obtained and the pKa for Artepillin $\mathrm{C}$ was determined. The influence of $\mathrm{pH}$ and concentration of Artepillin $\mathrm{C}$ on the optical absorption and emission properties of the compound were investigated by preparing solutions with concentrations of Artepillin C ranging from 10 to $100 \mu \mathrm{M}$ in citrate-phosphate buffer at $\mathrm{pH} 3.0,4.9$ and 7.0.

Optical absorption spectra were obtained with an AmersahmPharmacia Ultrospec 2100 pro spectrophotometer. A Hitachi F-7000 spectrofluorimeter, with polarizer filters for anisotropy experiments, was used for steady state fluorescence measurements. Fluorescence decays and time-resolved anisotropy were measured using single photon counting method. The excitation source was a Tsunami 3950 Spectra Physics titanium-sapphire laser, pumped by a Millennia X Spectra Physics solid state laser. The repetition rate of the pulses was set to $8.0 \mathrm{MHz}$ using the 3980 Spectra Physics pulse picker. The laser was tuned so that a third harmonic generator BBO crystal (GWN-23PL Spectra Physics) gave the $296 \mathrm{~nm}$ excitation pulses that were directed to an Edinburgh

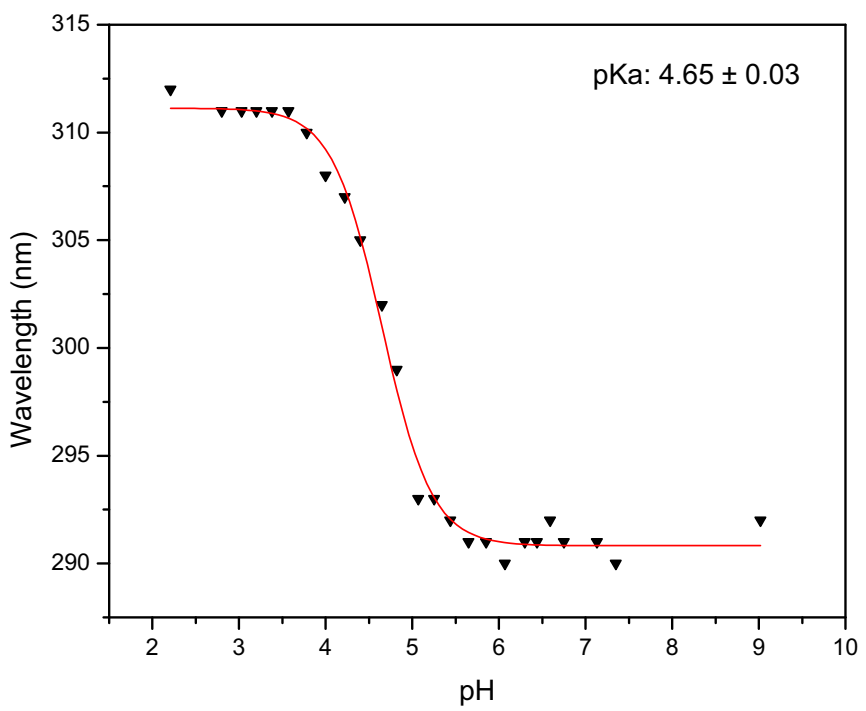

Fig. 3. Titration curve for Artepillin C: wavelength of the peak of the near UV absorption band, as a function of the $\mathrm{pH}$ of the medium. Concentration of Artepillin $\mathrm{C} 20 \mu \mathrm{M}$. 


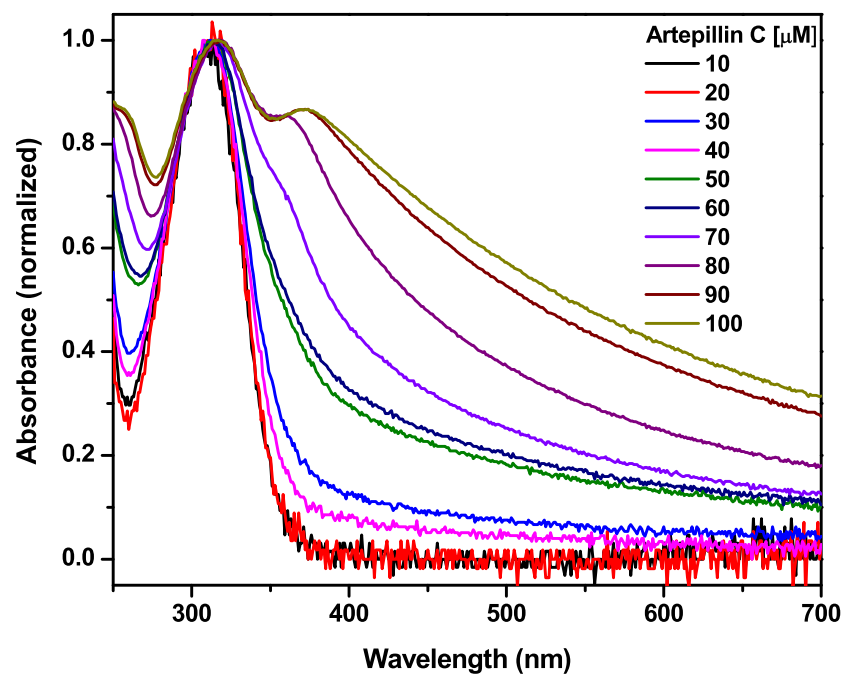

(a)

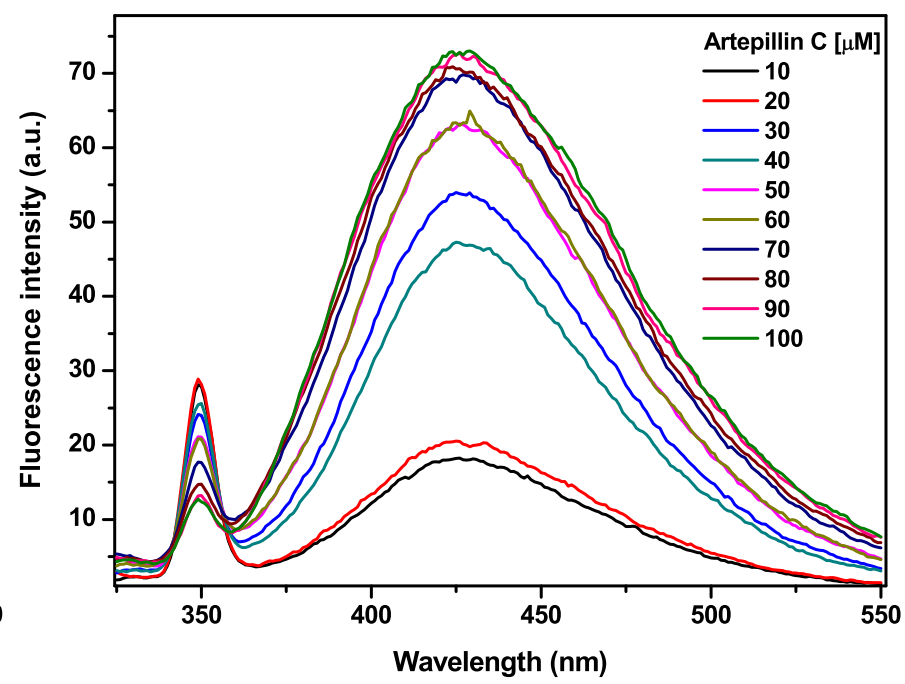

(b)

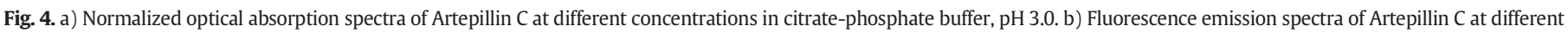
concentrations in citrate-phosphate buffer, $\mathrm{pH} 3.0$, excitation at $310 \mathrm{~nm}$. Temperature $25^{\circ} \mathrm{C}$.

FL900 spectrometer. The spectrometer was set in L-format configuration, the emission wavelength was selected by a monochromator, and emitted photons were detected by a refrigerated Hamamatsu R3809U microchannel plate photomultiplier. Soleil-Babinet compensator in the excitation beam and Glann-Thomson polarizer in the emission beam were used in anisotropy experiments. The FWHM of the instrument response function was typically $100 \mathrm{ps}$ and time resolution was 12 ps per channel and the software provided by Edinburgh Instruments was used to analyze the individual decays, which were fitted to multi-exponential curves.

$I(t)=\sum \alpha_{i} e^{\left(-t / \tau_{i}\right)}$

where $\alpha \mathrm{i}$ and $\tau \mathrm{i}$ are, respectively, pre-exponential factor and lifetime of the component $\mathrm{i}$ of decay. The quality of the fit was judged by the

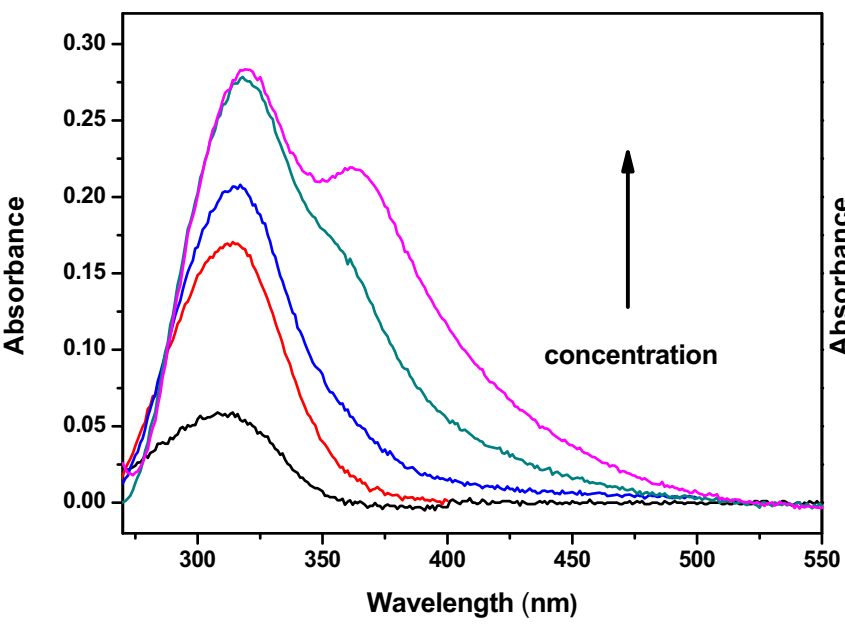

(a) analysis of the statistical parameter reduced- $\chi 2$ and by inspection of the residuals distribution.

\section{Results and Discussion}

\section{1. pH Effects: Determination of $p K a$}

Samples of Artepillin C were prepared in low concentration, $20 \mu \mathrm{M}$, and optical absorption spectra were measured in the $\mathrm{pH}$ range 2.6 to 9.2. At that concentration each spectrum was dominated by a main absorption band in the near UV region, whose peak displaced from 310 to $290 \mathrm{~nm}$ with the increase in $\mathrm{pH}$ (Fig. 2, peak normalized absorption spectra).

We expected that at such low concentration the changes in the acidbase equilibrium of the compound were the relevant factor associated to the changes in the main absorption band, and the shift in the

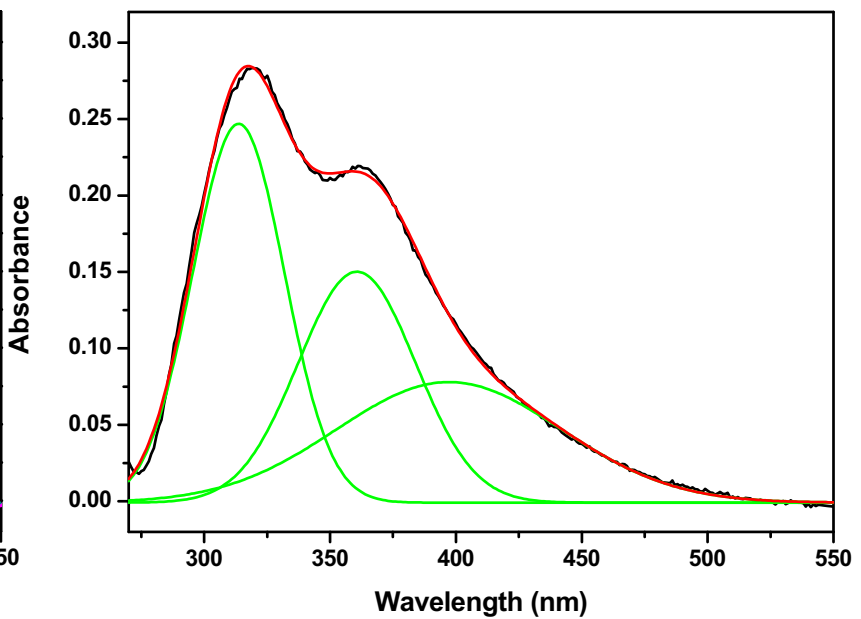

(b)

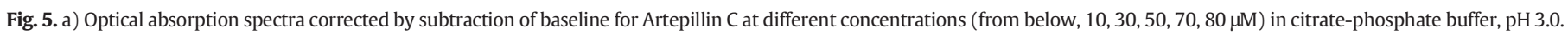
b) Fit (red) of Gaussian curves (green) to the spectrum (black) of Artepillin C $80 \mu \mathrm{M}$. 


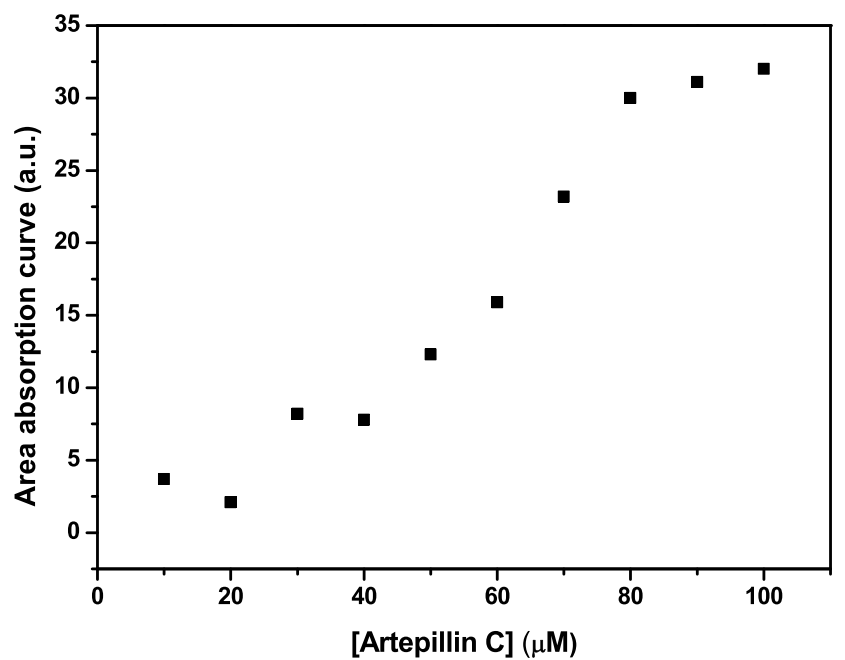

(a)

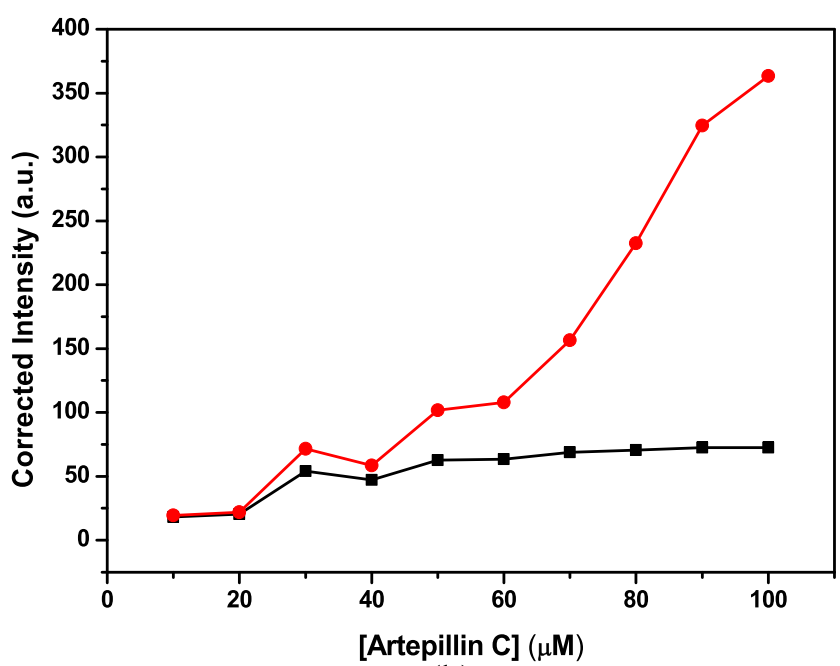

(b)

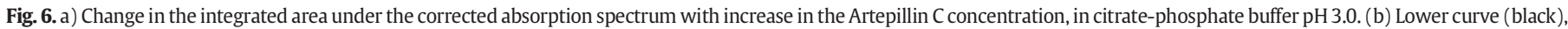

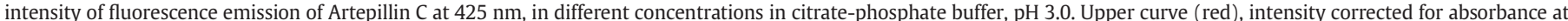
excitation and emission wavelength.

maximum wavelength of the absorption band reflects the changes in the protonation state of the carboxylic group. A titration curve, given by the plot of the wavelength of the absorption peak as function of $\mathrm{pH}$ allows the determination of the pKa of Artepillin $\mathrm{C}$ by finding the point of inflection of the fitted curve (Fig. 3). The value obtained was $4.65 \pm 0.03$, corresponding to the equilibrium between protonated and deprotonated forms of the carboxyl group of Artepillin C (Fig. 1).

Concomitant to changes in the peak position, the absorbance of Artepillin $\mathrm{C}$ raised with increase in the $\mathrm{pH}$ of the solution. The calculated molar absorption coefficient changed from $0.61 \times 10^{4} \mathrm{M}^{-1} \mathrm{~cm}^{-1}$ at acidic $\mathrm{pH}$, below $\mathrm{pH} 4.0$, to $2.13 \times 10^{4} \mathrm{M}^{-1} \mathrm{~cm}^{-1}$ in neutral $\mathrm{pH}$. The neutral protonated form of Artepillin $\mathrm{C}$, dominant when the $\mathrm{pH}$ of the medium is below 4.65 , has emission with the near UV band peaking at $305 \mathrm{~nm}$, and low molar absorption coefficient. The deprotonated form, dominant in $\mathrm{pH}$ values above 4.65 , possess a negative charge in the carboxyl group, and has the near UV absorption band displaced to $290 \mathrm{~nm}$, with increased molar absorption coefficient compared to the neutral species. The results suggest that in deprotonated Artepillin $C$ the electronic distribution is more delocalized and less structured than in the protonated or neutral species. This affects the magnitude of the static dipole moment in the ground and excited state, resulting in a blue-shift of the electronic absorption band as described for molecular complexes functionalized with carboxylic acid [19], and also for organic compounds like ortho-aminobenzoic acid and derivatives [20-22].

\subsection{Concentration Effects in Different pHs: Aggregation of Artepillin C}

The influence of concentration in the spectroscopic properties of Artepillin $\mathrm{C}$ was examined in three different $\mathrm{pHs}$ separately. We assumed that in $\mathrm{pH}$ values below (3.0) and above (7.0) the pKa of Artepillin $\mathrm{C}$, the compound is predominantly in neutral and anionic forms respectively. and at $\mathrm{pH}$ around the $\mathrm{pKa}$ both species are present.

\subsection{1. pH 3.0: Protonated Artepillin C}

Optical absorption spectra in citrate-phosphate buffer $\mathrm{pH} 3.0$ were obtained at Artepillin C concentrations in the range 10 to $100 \mu \mathrm{M}$ (Fig. 4a). The absorption band centered around $315 \mathrm{~nm}$ is present in all concentrations, and above $50 \mu \mathrm{M}$ of Artepillin C, a new band appears

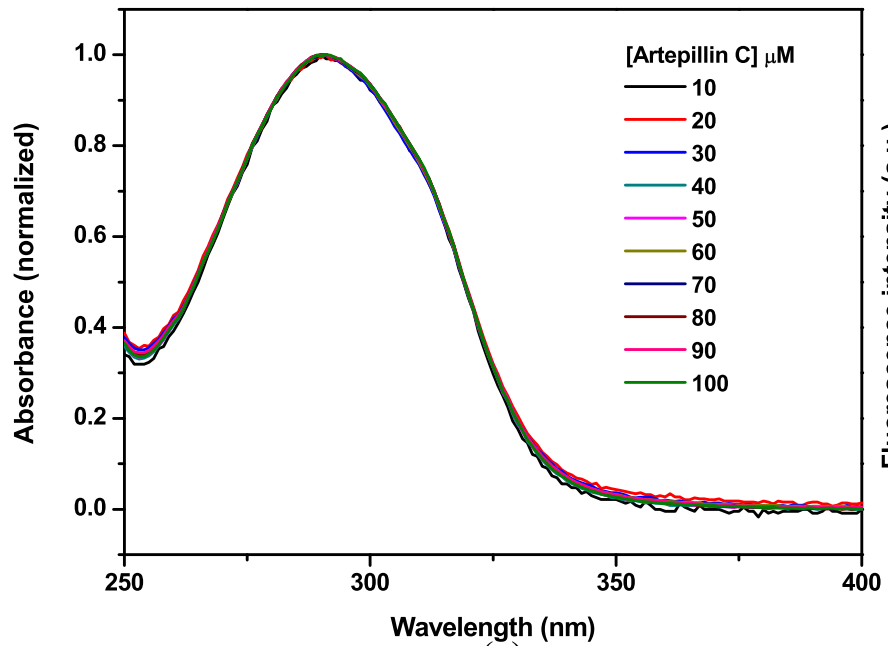

(a)

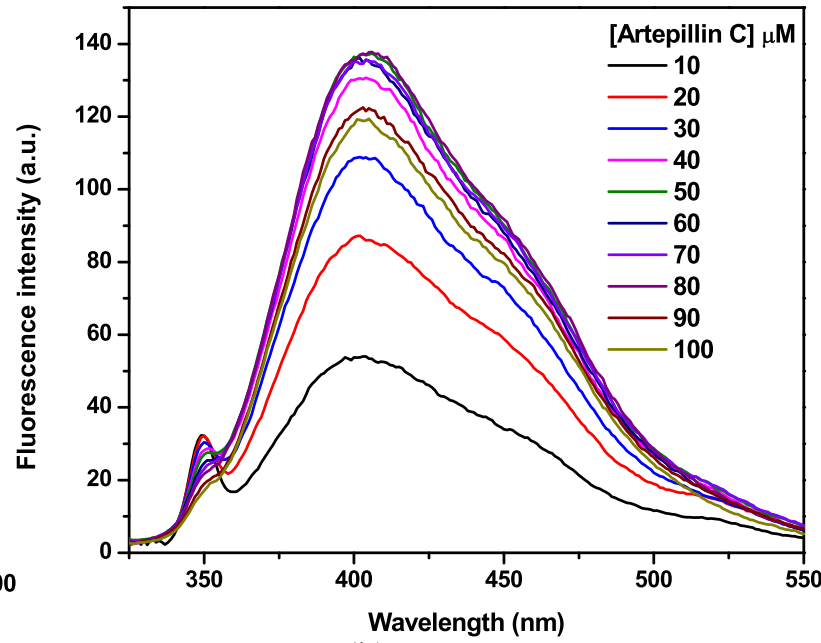

(b)

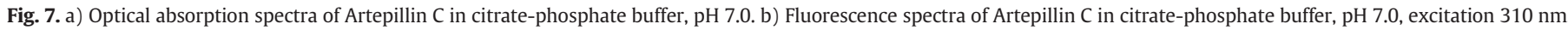
Temperature $25{ }^{\circ} \mathrm{C}$ 


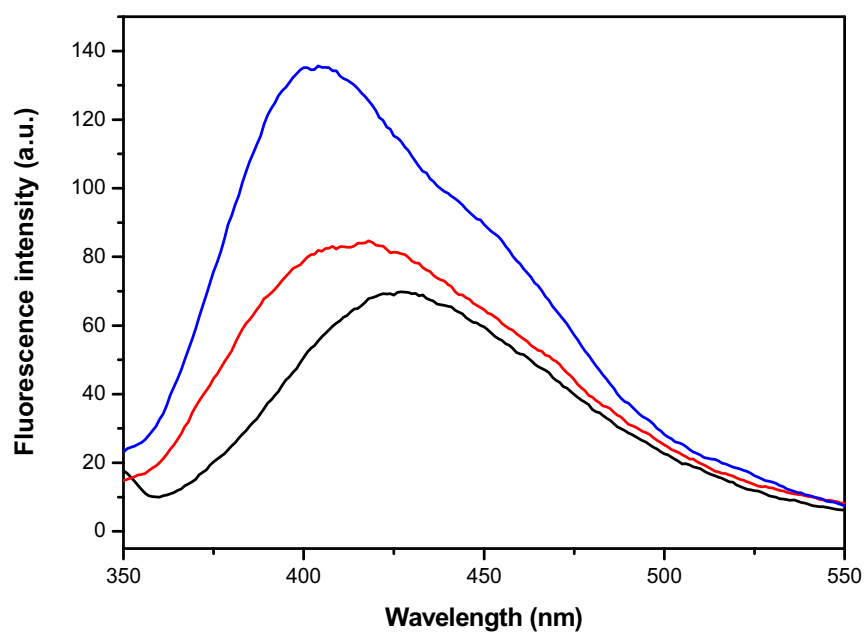

Fig. 8. Emission spectra of Artepillin C $80 \mu \mathrm{M}$ in pH 3.0 (black), 4.9 (red) and 7.0 (blue) Excitation wavelength $310 \mathrm{~nm}$. Temperature $25^{\circ} \mathrm{C}$.

around $360 \mathrm{~nm}$, whose intensity increases at higher concentrations. Fluorescence emission spectra of Artepillin $\mathrm{C}$ in concentrations between 10 and $100 \mu \mathrm{M}$ in citrate-phosphate buffer $\mathrm{pH} 3.0$ were recorded with excitation at $310 \mathrm{~nm}$, showing emission around $425 \mathrm{~nm}$ (Fig. 4b).

The changes in the absorption spectra are better visualized performing baseline subtraction in the spectra (Fig. 5a). It is clearly seen that in concentrations above $50 \mu \mathrm{M}$ a band at wavelength above $350 \mathrm{~nm}$ becomes discernible, and the spectra broadens at higher concentrations of Artepillin C, above $70 \mu \mathrm{M}$. The corrected spectra can be fitted to gaussians bands and for the lower concentrations, below 30 $\mu \mathrm{M}$, one gaussian centered around $312 \mathrm{~nm}$ is enough to fit the spectra. At intermediate concentrations $(40-60 \mu \mathrm{M})$ appears the contribution of a second gaussian centered around $347 \mathrm{~nm}$. In still higher concentrations, a third broad gaussian, centered above $400 \mathrm{~nm}$ contributes to the spectra (in Fig. 5b, illustration of the fit to three gaussians performed to the spectrum of Artepillin C $80 \mu \mathrm{M}$; more details can be seen in Supporting Material 1).

As described above, the carboxyl group is protonated and the molecule is in the electrically neutral state. As the molecules are in neutral state, it is possible that they aggregate, due to hydrophobic interactions [22]. The species formed can be in the form of J-aggregates, expressed by

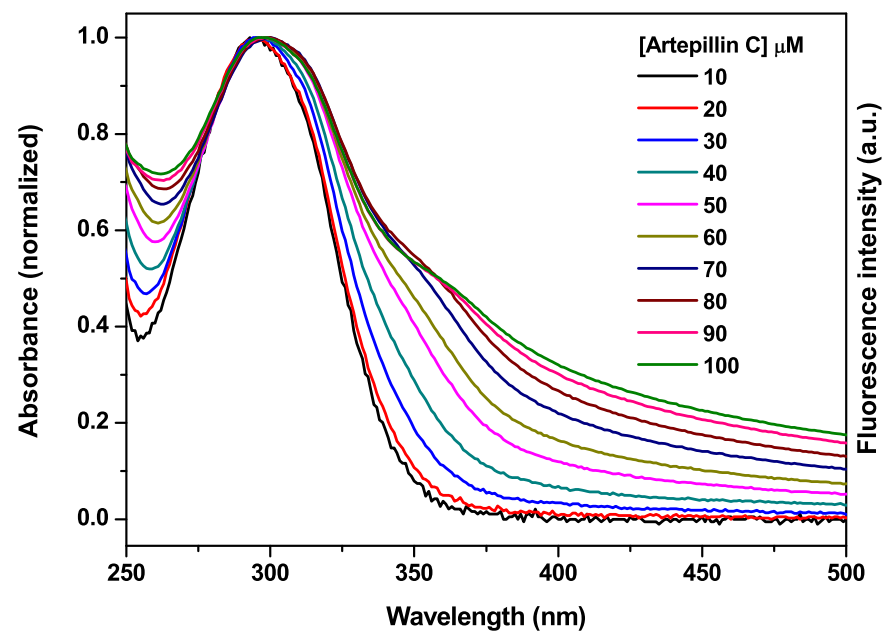

(a) the longer wavelength (around $350 \mathrm{~nm}$ ) in the absorption band [23] An approximately linear increase in the area under the absorption spectrum is observed for concentrations below $60 \mu \mathrm{M}$ (Fig. 6a). Above that concentration, aggregated species increase the cross section for absorption, with corresponding increase in the area under the absorption spectrum.

Under excitation at $310 \mathrm{~nm}$, the emission spectrum of Artepillin C is characterized by a broad emission centered around $425 \mathrm{~nm}$ independent of its concentration (Fig. 4b). The intensity of emission does not increase linearly with the concentration due to inner filter effects caused by the high absorbance of the more concentrated samples (Fig. 6b). As the more concentrated solutions present high absorbance both at excitation and emission wavelengths, inner filter effects become appreciable. The corrections for inner filter attenuation applied to the emission intensity, leads to the expected increase of emission with increase in the concentration of Artepillin C.

\subsection{2. pH 7.0: Deprotonated Artepillin C}

At neutral pH, optical absorption spectra of Artepillin $\mathrm{C}$ in the concentration range 10 to $100 \mu \mathrm{M}$ show the near UV absorption band centered at $291 \mathrm{~nm}$, corresponding to the deprotonated and negatively charged form of the molecule (Fig. 7a). The absorbance at the peak follows the Beer-Lambert law, with linear increase with the concentration of Artepillin C (Supporting Material 2).

The fluorescence emission spectra were obtained with excitation at $310 \mathrm{~nm}$. The spectra are quite broad, with maximum emission around $400 \mathrm{~nm}$. The intensities do not increase linearly with the concentration, because the measurements are affected by the high extinction coefficient of the absorption at the excitation wavelength. Intensities corrected for inner filter effects showed an upward deviation from linearity. A comparison for the emission spectra at different pHs, with excitation at $310 \mathrm{~nm}$, is illustrated in Fig. 8. Similar to the absorption spectra, the spectral position of the emission band depends on the $\mathrm{pH}$ of medium: the wavelength for maximum emission locates at $425 \mathrm{~nm}$ in the protonated form of Artepillin C ( $\mathrm{pH} 3.0$ ); close to the pKa, the maximum emission occurs at $410 \mathrm{~nm}(\mathrm{pH} 4.9)$; and for the deprotonated species of Artepillin C, the emission peaks in $400 \mathrm{~nm}$ ( $\mathrm{pH} 7.0$ ). The blue-shift observed in fluorescence emission spectra from protonated to deprotonated is also related to the delocalized and less structured electronic transition in deprotonated compounds, as discussed for the absorption spectra of Artepillin C.

At $\mathrm{pH} 7.0$, it is noticeable the appearance of a broad red shifted band with emission above $450 \mathrm{~nm}$. One possibility for this long wavelength

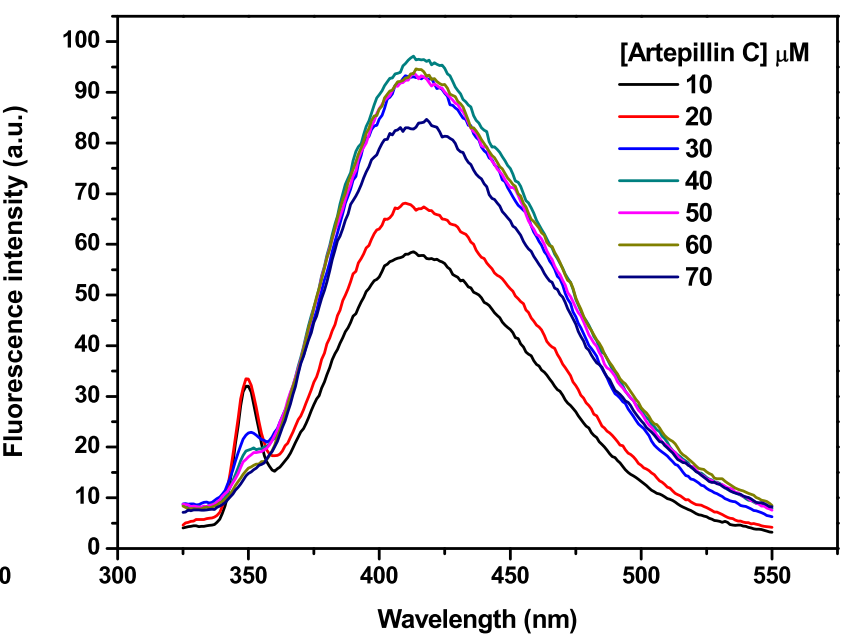

(b)

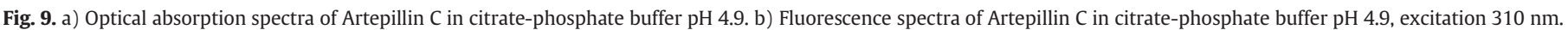
Temperature $25^{\circ} \mathrm{C}$. 


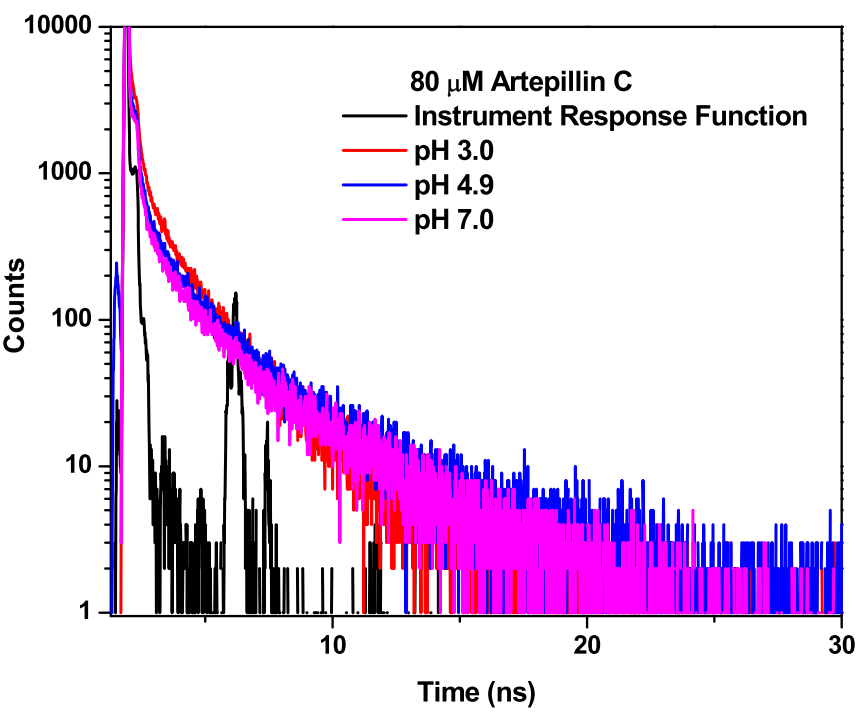

Fig. 10. Intensity decay profiles of Artepillin $\mathrm{C} 80 \mu \mathrm{M}$, at pH 3.0 (red), 4.9 (blue) and 7.0 (pink). Excitation $296 \mathrm{~nm}$, emission $400 \mathrm{~nm}$, temperature $25^{\circ} \mathrm{C}$. The black curve represents the Instrument Response Function (IRF).

emission is the occurrence of isomeric forms of deprotonated anionic Artepillin C. Different isomeric forms involving the carboxy group result in distinct interactions with the proton donor water molecules, as observed for example in ortho-aminobenzoic or anthranilic acid molecules, both experimentally as in electronic structure calculations $[20,24]$. Due to different solvent relaxation processes for the excited state of the transition dipoles from the isomers, the emission wavelength may be different, with the occurrence of dual emission [22,25]. In low $\mathrm{pH}$, the neutral protonated isomers should have similar interactions via hydrogen bonds with the water molecules.

\subsection{3. $\mathrm{pH}$ 4.9: Protonated and Deprotonated Species}

At this $\mathrm{pH}$, Artepillin $\mathrm{C}$ is close to the equilibrium between protonated and deprotonated species. The optical absorption spectra are broad and have maximum around $296 \mathrm{~nm}$, with a noticeable contribution from a band with maximum around $310 \mathrm{~nm}$ (Fig. 9a). Compared to the spectra obtained for the titration curve, the data indicate the coexistence of both protonated and deprotonated forms of the carboxy group in Artepillin C. At low concentration, $20 \mu \mathrm{M}$, absorption spectrum can be fitted to two gaussians, one centered at $293 \mathrm{~nm}$ with height 0.98 and the other at $313 \mathrm{~nm}$, with height 0.09 . The spectrum is dominated by the deprotonated species because of its higher molar absorptivity $(2.13$ $\left.\times 10^{4} \mathrm{M}^{-1} \mathrm{~cm}^{-1}\right)$ compared to the protonated form $\left(0.61 \times 10^{4} \mathrm{M}^{-}\right.$ $\left.{ }^{1} \mathrm{~cm}^{-1}\right)$. On the other hand, at high Artepillin C concentration, 100 $\mu \mathrm{M}$, the absorbance is fitted with three gaussians centered at 298, 318 and $334 \mathrm{~nm}$, with heights $0.42,0.42$ and 0.45 respectively and we can observe the contribution of a broad band at longer wavelength, indicating that probably aggregates are formed involving the protonated forms of Artepillin C, present at $\mathrm{pH}$ 4.9. Fitting parameters for optical absorption spectra of 20 and $100 \mu \mathrm{M}$ of Artepillin C can be found at Supporting Material 3.
Fluorescence emission spectra were obtained exciting the samples at $310 \mathrm{~nm}$ (Fig. 7b). The spectra are relatively broad, with maximum emission around $410 \mathrm{~nm}$. The intensities do not increase linearly with the concentration, because the measurements are affected by the high extinction coefficient of the absorption at the excitation wavelength.

\subsection{Fluorescence Intensity and Anisotropy Time-resolved Decay}

In time-resolved experiments, samples containing $20 \mu \mathrm{M}$ or $80 \mu \mathrm{M}$ of Artepillin $\mathrm{C}$ in the $\mathrm{pH} 3.0,4.9$ and 7.0 were excited with pulsed laser tuned at $296 \mathrm{~nm}$. The intensity decay was complex, and decay profiles required three-exponential curves for adequate fit (Fig. 10 and Table 1). The component associated to the short lifetime, around $50 \mathrm{ps}$, is predominant, showing the highest value of the normalized pre-exponential factor. Intermediate lifetimes around $0.60-0.80 \mathrm{~ns}$ were also present, and best fit was obtained with inclusion of a very small contribution of a long lifetime components higher than $2.0 \mathrm{~ns}$.

Average lifetimes were calculated using

$$
<\tau>=\frac{\sum \alpha_{i} \tau_{i}^{2}}{\sum \alpha_{i} \tau_{i}}
$$

obtained from the usual definition of average applied to Eq. (1) and the calculated values are in the hundred-picosecond region, showing that very efficient non-radiative processes dominate the decay from the excited state.

Steady state anisotropy was measured in $\mathrm{pH} 3.0,4.9$ and 7.0 and the values obtained are relatively high: $0.209,0.163$ and 0.201 for $20 \mu \mathrm{M}$ and $0.189,0.253$ and 0.199 for $80 \mu \mathrm{M}$ of Artepillin C, respectively. The results must consider that steady state anisotropy depends on both intensity decay and anisotropy decay [18]. On the above pHs, the rotational correlation times for the anisotropy decay were $0.445,0.461$ and $0.590 \mathrm{~ns}$ for $20 \mu \mathrm{M}$ and $0.541,0.728$ and $0.645 \mathrm{~ns}$ for $80 \mu \mathrm{M}$ of Artepillin C, respectively. As the dominant lifetime values are very short (Table 1 ), the excited state is depopulated before the emission dipoles perform rotational diffusion. Therefore, the emission occurs much before the fluorophores rotate, and the value of the intensity component perpendicular to the direction of excitation is small, resulting in high values for the steady state anisotropy. From the time-resolved data it was possible to calculate a mean value for the anisotropy [26], resulting in values between 0.13 and 0.28 (Table 2 ).

\section{Conclusions}

Optical absorption and fluorescence spectroscopies allowed the identification of different molecular arrangements of Artepillin C, the major component of green propolis, in aqueous solutions at different pHs. The compound is derived from cinnamic acid, presenting a carboxyl group susceptible to protonation-deprotonation processes. In conditions of low concentration, acid-base titration monitoring the spectral position of the near UV absorption band, resulted in the pKa value of 4.65 for the carboxylic group in Artepillin C.

Concentration effects observed in optical absorption spectra were dependent on the $\mathrm{pH}$ of the medium. In acidic $\mathrm{pH}$, below the $\mathrm{pKa}$ value, an absorption band raised around $350 \mathrm{~nm}$ when the Artepillin C concentration was higher than $50 \mu \mathrm{M}$. As the compound at that $\mathrm{pH}$ is

Table 1

Intensity decay parameters for Artepillin C in citrate-phosphate buffer, pH 3.0, 4.9 and 7.0; emission wavelength at $400 \mathrm{~nm}$. Temperature $25^{\circ} \mathrm{C}$.

\begin{tabular}{|c|c|c|c|c|c|c|c|c|}
\hline pH - Citrate-phosphate buffer & Artepillin C concentration $(\mu \mathrm{M})$ & $\tau_{1}(\mathrm{~ns})$ & $\alpha_{1}$ & $\tau_{2}(\mathrm{~ns})$ & $\alpha_{2}$ & $\tau_{3}(\mathrm{~ns})$ & $\alpha_{3}$ & $<\tau>$ \\
\hline 3.0 & 20 & 0.051 & 0.940 & 0.60 & 0.054 & 3.45 & 0.0034 & 0.46 \\
\hline 4.9 & & 0.066 & 0.970 & 0.66 & 0.026 & 3.42 & 0.0052 & 0.62 \\
\hline 7.0 & & 0.058 & 0.980 & 0.8 & 0.017 & 3.2 & 0.0012 & 0.18 \\
\hline 3.0 & 80 & 0.036 & 0.984 & 0.54 & 0.014 & 2.01 & 0.0020 & 0.20 \\
\hline 4.9 & & 0.032 & 0.993 & 0.81 & 0.006 & 4.05 & 0.0006 & 0.26 \\
\hline 7.0 & & 0.028 & 0.996 & 0.89 & 0.004 & 4.18 & 0.0004 & 0.20 \\
\hline
\end{tabular}


Table 2

Steady state anisotropy $\left(A_{S}\right)$, rotational correlation time $(\varphi)$, initial anisotropy $(B)$ and calculated average anisotropy $<A>$.

\begin{tabular}{llllll}
\hline $\begin{array}{l}\text { pH - Citrate-phosphate } \\
\text { buffer }\end{array}$ & $\begin{array}{l}\text { Artepillin C concentration } \\
(\mu \mathrm{M})\end{array}$ & $\mathrm{A}_{\mathrm{s}}$ & $\begin{array}{l}\varphi \\
(\mathrm{ns})\end{array}$ & $\mathrm{B}$ & $<\mathrm{A}>$ \\
\hline 3.0 & 20 & 0.209 & 0.445 & 0.396 & 0.169 \\
4.9 & & 0.163 & 0.461 & 0.356 & 0.205 \\
7.0 & & 0.201 & 0.590 & 0.372 & 0.262 \\
3.0 & 80 & 0.189 & 0.541 & 0.224 & 0.127 \\
4.9 & & 0.253 & 0.728 & 0.336 & 0.213 \\
7.0 & & 0.199 & 0.645 & 0.352 & 0.283 \\
\hline
\end{tabular}

electrically neutral, aggregation could be occurring, resulting in the rising of long wavelength absorption band. In $\mathrm{pH} 4.9$, there must be an equilibrium between protonated and deprotonated species, that coexists contributing to the spectral characteristics of the compound. In neutral $\mathrm{pH}$ the deprotonated negatively charged form of Artepillin C dominates, which absorbs at $290 \mathrm{~nm}$ and emits with maximum at $400 \mathrm{~nm}$. It is possible that isomeric forms are present in the solution, with different interaction with the aqueous environment and distinct relaxation processes, leading to dual emission at 400 and $450 \mathrm{~nm}$.

Intensity decays at the different $\mathrm{pHs}$ were fitted to three exponential function. The decay was fast, dominated by a very short lifetime component, around $0.060 \mathrm{~ns}$. The fast decay precluded the rotational diffusion of the excited transition dipole, and emission occurs before fluorescence depolarization, resulting in values of the fluorescence anisotropy higher than could be expected for monomeric forms of the compound.

Artepillin $C$ is known by the affinity with amphiphilic aggregates, in processes that can be relevant to its biological activity. The results described here points to the importance of the knowledge of the protonation state of the molecule, that can be relevant in processes mediated by biological membranes. As a first systematic compilation of spectroscopic data of Artepillin C, there still remain important questions deserving attention, like the influence of isomerization in the optical properties of the molecule. We believe that further studies including, e.g., electronic structure calculations and molecular dynamics simulations could be helpful to improve the understanding of the absorption and emission properties of Artepillin C.

\section{Acknowledgements}

This work was developed with the financial support of São Paulo State Research Foundation (FAPESP), National Council for Scientific and Technological Development $(\mathrm{CNPq})$ and Coordination for the Improvement of Higher Education Personnel (CAPES). W.M.Pazin is grateful to FAPESP (2016/09633-4) for the post-doctoral fellowship and I.J.Camuri is grateful to CAPES for the master fellowship, both received during the development of this research work. A.S Ito thanks CNPq for research fellowship (305771/2016-7).

\section{Conflicts of interest}

None.

\section{Appendix A. Supplementary data}

Supplementary data to this article can be found online at https://doi. org/10.1016/j.saa.2018.02.059.

\section{References}

[1] J.M. Sforcin, Propolis and the immune system: a review, J. Ethnopharmacol. 113 (2007) 1-14, https://doi.org/10.1016/j.jep.2007.05.012.

[2] J.F. Campos, U.P. dos Santos, P. dos S. da Rocha, M.J. Damião, J.B.P. Balestieri, C.A.L Cardoso, E.J. Paredes-Gamero, L.M. Estevinho, K. de Picoli Souza, E.L. dos Santos,
Antimicrobial, antioxidant, anti-inflammatory, and cytotoxic activities of propolis from the stingless bee Tetragonisca fiebrigi (Jataí). Evidence-Based Complement. Altern. Med. 2015 (2015) 1-11, https://doi.org/10.1155/2015/296186.

[3] J.M. Sforcin, V. Bankova, Propolis: is there a potential for the development of new drugs? J. Ethnopharmacol. 133 (2011) 253-260, https://doi.org/10.1016/j.jep. 2010.10 .032$.

[4] A. Salatino, C.C. Fernandes-Silva, A.A. Righi, M.L.F. Salatino, Propolis research and the chemistry of plant products, Nat. Prod. Rep. 28 (2011) 925, https://doi.org/10.1039/ c0np00072h.

[5] A.C.H.F. Sawaya, I.B.S.C, M.C. Marcucci, Analytical methods applied to diverse types of Brazilian propolis, Chem. Cent. J. 5 (2011) 27, https://doi.org/10.1186/1752153X-5-27.

[6] M.-R. Ahn, K. Kunimasa, T. Ohta, S. Kumazawa, M. Kamihira, K. Kaji, Y. Uto, H. Hori, H. Nagasawa, T. Nakayama, Suppression of tumor-induced angiogenesis by Brazilian propolis: major component artepillin C inhibits in vitro tube formation and endothelial cell proliferation, Cancer Lett. 252 (2007) 235-243, https://doi.org/10.1016/ j.canlet.2006.12.039.

[7] S. Kumazawa, T. Hamasaka, T. Nakayama, Antioxidant activity of propolis of various geographic origins, Food Chem. 84 (2004) 329-339, https://doi.org/10.1016/S03088146(03)00216-4.

[8] H. Aga, T. Shibuya, T. Sugimoto, Isolation and identification of antimicrobial compounds in Brazilian propolis, Biosci. Biotechnol. Biochem. 58 (1994) 945-946, https://doi.org/10.1080/bbb.58.945.

[9] M.C. Marcucci, F. Ferreres, C. García-Viguera, V.S. Bankova, S.L. de Castro, A.P. Dantas, P.H.M. Valente, N. Paulino, Phenolic compounds from Brazilian propolis with pharmacological activities, J. Ethanopharmacol. 74 (2001) 105-112.

[10] W.M. Pazin, L. da M. Mônaco, A.E. Egea Soares, F.G. Miguel, A.A. Berretta, A.S. Ito, Antioxidant activities of three stingless bee propolis and green propolis types, J. Apic. Res. 56 (2017) 40-49, https://doi.org/10.1080/00218839.2016.1263496.

[11] H. Hattori, K. Okuda, T. Murase, Y. Shigetsura, K. Narise, G.L. Semenza, H. Nagasawa, Isolation, identification, and biological evaluation of HIF-1-modulating compounds from Brazilian green propolis, Bioorg. Med. Chem. 19 (2011) 5392-5401, https:// doi.org/10.1016/j.bmc.2011.07.060.

[12] W.M. Pazin, D. da S. Olivier, N. Vilanova, A.P. Ramos, I.K. Voets, A.E.E. Soares, A.S. Ito, Interaction of artepillin C with model membranes, Eur. Biophys. J. 46 (2017) 383-393, https://doi.org/10.1007/s00249-016-1183-5.

[13] Y. Kato, S. Ozawa, C. Miyamoto, Y. Maehata, A. Suzuki, T. Maeda, Y. Baba, Acidic extracellular microenvironment and cancer, Cancer Cell Int. 13 (2013) 89, https://doi. org/10.1186/1475-2867-13-89.

[14] Y. Uto, S. Ae, D. Koyama, M. Sakakibara, N. Otomo, M. Otsuki, H. Nagasawa, K.L. Kirk, $\mathrm{H}$. Hori, Artepillin C isoprenomics: design and synthesis of artepillin C isoprene analogues as lipid peroxidation inhibitor having low mitochondrial toxicity, Bioorg. Med. Chem. 14 (2006) 5721-5728, https://doi.org/10.1016/j.bmc.2006.04.015.

[15] I. Nakanishi, Y. Uto, K. Ohkubo, K. Miyazaki, H. Yakumaru, S. Urano, H. Okuda, J.I. Ueda, T. Ozawa, K. Fukuhara, S. Fukuzumi, J. Nagasawa, H. Hori, N. Ikota, Efficient radical scavenging ability of artepillin $\mathrm{C}$, a major component of Brazilian propolis, and the mechanism, Org. Biomol. Chem. 1 (2003) 1452-1454, https://doi.org/10. 1039/B302098c.

[16] S. Manda, I. Nakanishi, K. Ohkubo, Y. Uto, T. Kawashima, H. Hori, K. Fukuhara, H. Okuda, T. Ozawa, N. Ikota, S. Fukuzumi, K. Anzai, Enhanced radical-scavenging activity of naturally-oriented artepillin C derivatives, Chem. Commun. (Camb.) (2008) 626-628, https://doi.org/10.1039/b715973k

[17] S.R. McKeown, Defining normoxia, physoxia and hypoxia in tumours-implications for treatment response, Br. J. Radiol. 87 (2014), 20130676. https://doi.org/10.1259/ bjr.20130676.

[18] L.S. Berlim, A.G. Bezerra, W.M. Pazin, T.S. Ramin, W.H. Schreiner, A.S. Ito, Photophysical properties of flavonoids extracted from Syngonanthus nitens, the golden grass, J. Lumin. 194 (2018) 394-400, https://doi.org/10.1016/j.jlumin.2017. 10.040.

[19] E. Badaeva VV. Albert S. Kilina A. Koposov, M. Sykora, S. Tretiak, Effect of deprotonation on absorption and emission spectra of Ru(II)-bpy complexes functionalized with carboxyl groups, Phys. Chem. Chem. Phys. 12 (2010) 8902-8913, https://doi. org/10.1039/b924910a.

[20] M. Takara, A.S. Ito, General and specific solvent effects in optical spectra of orthoaminobenzoic acid, J. Fluoresc. 15 (2005) 171-177, https://doi.org/10.1007/ s10895-005-2525-3.

[21] M. Takara, J.K. Eisenhut, I.Y. Hirata, L. Juliano, A.S. Ito, Solvent effects in optical spectra of ortho-aminobenzoic acid derivatives, J. Fluoresc. 19 (2009) 1053-1060, https://doi.org/10.1007/s10895-009-0505-8.

[22] C.A. Marquezin, I.Y. Hirata, L. Juliano, A.S. Ito, Spectroscopic characterization of 2amino-N-hexadecyl-benzamide (AHBA), a new fluorescence probe for membranes, Biophys. Chem. 124 (2006) 125-133, https://doi.org/10.1016/j.bpc.2006.06.002.

[23] L.P.F. Aggarwal, I.E. Borissevitch, On the dynamics of the TPPS4 aggregation in aqueous solutions: successive formation of $\mathrm{H}$ and J aggregates, Spectrochim. Acta - Part A Mol. Biomol. Spectrosc. 63 (2006) 227-233, https://doi.org/10.1016/j.saa.2005.05. 009.

[24] D. da S. Olivier, A.S. Ito, S.E. Galembeck, Microhydration effects on geometric properties and electronic absorption spectra of ortho-aminobenzoic acid, Spectrochim. Acta Part A Mol. Biomol. Spectrosc. 147 (2015) 328-333, https://doi.org/10.1016/j. saa.2015.03.108.

[25] A. Amat, C. Clementi, F. De Angelis, A. Sgamellotti, S. Fantacci, Absorption and emission of the apigenin and luteolin flavonoids: a TDDFT investigation $\dagger$. J. Phys. Chem. A 113 (2009) 15118-15126, https://doi.org/10.1021/jp9052538.

[26] A.S. Ito, A.P. Rodrigues, W.M. Pazin, M.B. Barioni, Fluorescence depolarization analysis of thermal phase transition in DPPC and DMPG aqueous dispersions, J. Lumin. (2015)https://doi.org/10.1016/j.jlumin.2014.09.051. 